http://jmscr.igmpublication.org/home/ ISSN (e)-2347-176x ISSN (p) 2455-0450

crossref DOI: https://dx.doi.org/10.18535/jmscr/v7i7.62

\title{
Clinico-Epidemiological Profile of Primary IgA Nephropathy - An Institutional Experience in South India
}

\author{
Authors \\ Sivaganesh @ Porko. G ${ }^{\text {** }}$, Isha Garg ${ }^{2}$, Pritilata Rout ${ }^{3}$ \\ ${ }^{1}$ Assistant Professsor, Department of Pathology, Sri Lakshmi Narayana Institute of Medical Sciences, \\ Pondicherry, India \\ ${ }^{2,3}$ Professor, Department of Pathology, St. John's Medical College and Hospital, Bangalore, Karnataka, \\ India \\ *Corresponding Author \\ Dr Sivaganesh@ Porko. G
}

Assistant Professsor, Department of Pathology, Sri Lakshmi Narayana Institute of Medical Sciences, Pondicherry, India - 605009

\section{Abstract}

Background: IgA nephropathy is the most common primary glomerulonephritis worldwide. Prognosis depends on the class of IgA nephropathy. There are only few studies to document the prevalence or clinicopathological spectrum of Primary IgA nephropathy in India.

Objectives: To study the clinic-epidemiological profile of primary IgA nephropathy.

Methodology: The study included renal biopsies diagnosed to have primary IgA nephropathy, received by the Department of Pathology, St. John's Medical College, Bangalore during a period of 10 years from January 2004 to December 2013. The study was both retrospective ((January 2004 to April 2012) and prospective (May 2012 to December 2013). The clinical data and laboratory findings were retrieved from the Medical Records Department of St. John's Medical College \& Hospital, Bangalore in all cases. The histological sections were reviewed along with the immunofluorescence findings and the relevant clinical data was analysed

Results: Out of 123 cases studied, age group ranged from 4 years to 70 years with the largest incidence in the 20 - 30 years age group (35\%) and an average age of 32.74 years, males predominated $(70.7 \%)$ with a male: female ratio being 2.4:1. Hypertension was found in 48(39\%) cases, hematuria in 53(43\%) cases and proteinuria in $51(42 \%)$ cases.

Summary and Conclusion: The incidence of IgAN was 2.4 times more common in males than in females. Haas class IV was the most common class. Hematuria was the most common clinical presentation. This study necessitates for early intervention strategies as well as screening programmes, not only to identify and treat the patients, but also for a better understanding of the factors which lead to this rapid and early progression.

Keywords: IgA nephropathy, Haas classification, hematuria, proteinuria.

\section{Introduction}

IgA nephropathy is the most common primary glomerulonephritis worldwide ${ }^{1}$. It is defined as
IgA dominant or co-dominant mesangial deposits excluding lupus nephritis ${ }^{2}$. Prognosis depends on the class of $\operatorname{IgA}$ nephropathy. The prevalence of 
IgA nephropathy among glomerular diseases and its incidence in the general population show considerable variation among geographic regions. A higher incidence is noted in Asian countries including India. In Asia, Singapore ${ }^{3,}$ Japan ${ }^{4}$ and China $^{5}$ have a very high prevalence of $\operatorname{IgA}$ nephropathy. The prevalence of IgA nephropathy in India varies with geographical regions. IgA nephropathy has been reported in all age groups with a peak incidence in the second/third decade of life with a higher prevalence in males ${ }^{6}$

The exact pathogenesis of the disease is unknown. The current hypothesis is that mucosal antigenic exposure in genetically susceptible individual results in the generation of nephritogenic IgA antibodies that form complexes in the circulation and get deposited in the glomeruli leading to glomerular injury The pathogenetic mechanism involved could be the production of an abnormal $\operatorname{IgA} 1$ with the subsequent generation of $\mathrm{IgG}$ and probably $\operatorname{IgA} 1$ antibodies directed against this. IgA-Immune complex formation may then occur either within the circulation or in situwithin the glomerulus and results in mesangial cell activation and glomerular injury ${ }^{7}$.

$\operatorname{Ig} \mathrm{A}$ nephropathy can occur in individuals of virtually any age, from young children to the elderly but occurs most commonly between the ages of 10 and 40 years $^{8}$. Most studies show a male predominance, with an overall average male: female ratio of approximately $2: 1^{9}$. The two major clinical presentations of primary IgA nephropathy are asymptomatic urinary abnormalities and macroscopic hematuria, the former being more common in adults and the latter in children ${ }^{10}$. Hypertension is noted in approximately $25 \%$ of patients at presentation ${ }^{10}$.

Most patients with IgA nephropathy present with some degree of proteinuria. Proteinuria is often mild, and nephrotic range proteinuria is relatively uncommon. The frequency of renal insufficiency at the time of initial presentation or diagnosis likewise varies between different studies.Many clinical parameters and laboratory findings have been reported to correlate with clinical outcomes in patients with IgA nephropathy.Reduced GFR (or elevated serum creatinine), severe proteinuria (defined in different studies as greater than 1 g/day, at least $2 \mathrm{~g} /$ day, at least $3 \mathrm{~g} /$ day, or nephrotic range), and hypertension were each found to be independent predictors of progression to end-stage renal disease (ESRD).

This study is being done to build up on the data on the clinico-epidemiological profile in Primary IgA nephropathy. There are only few studies to document the prevalence or clinicopathological spectrum of Primary IgA nephropathy in India.

\section{Objectives}

To study the clinic-epidemiological profile of primary IgA nephropathy.

\section{Materials}

This study included renal biopsies diagnosed to have primary IgA nephropathy, received by the Department of Pathology, St. John's Medical College, Bangalore during a period of 10 years from January 2004 to December 2013. The study was both retrospective ((January 2004 to April 2012) and prospective (May 2012 to December 2013). The clinical data and laboratory findings were retrieved from the Medical Records Department of St. John's Medical College \& Hospital, Bangalore in all cases. The histological sections were reviewed along with the immunofluorescence findings and the relevant clinical data was analysed

\section{Methods}

\section{Selection of cases}

\section{Inclusion criteria}

1) Confirmation by direct immunofluorescence of atleast 2+ positivity with $\operatorname{Ig}$ A antiserum, with $\operatorname{Ig} \mathrm{A}$ being the dominant or the co-dominant immunoglobulin deposited.

2) Availability of at least 5 glomeruli (light microscopy + immunofluorescence) for evaluation. 


\section{Exclusion Criteria}

1) Exclusion of other systemic diseases which can affect/alter the morphology- for example, systemic lupus erythematosus, diabetes mellitus, etc

2) Exclusion of secondary causes of $\operatorname{IgA}$ nephropathy, such as Henoch Schonleinpurpura, liver diseases.

\section{Clinical and laboratory data}

The age, sex, clinical presentation (hypertension, hematuria \& proteinuria) were collected/retrieved from the records and the data was tabulated.

\section{Results}

The study group included 123 cases that fulfilled the inclusion criteria

\section{Age Distribution}

The study group had a wide range of age, ranging from 4 years to 70 years with the largest incidence in the $20-30$ years age group (35\%) and an average age of 32.74 years. (Table 1, Table $2 \&$ Fig 1)

Table 1: Age at presentation of the cases

\begin{tabular}{|l|c|c|c|c|c|}
\hline & $\mathrm{N}$ & Minimum & Maximum & Mean & Median \\
\hline Age (years) & 123 & 4 & 70 & 32.74 & 36 \\
\hline
\end{tabular}

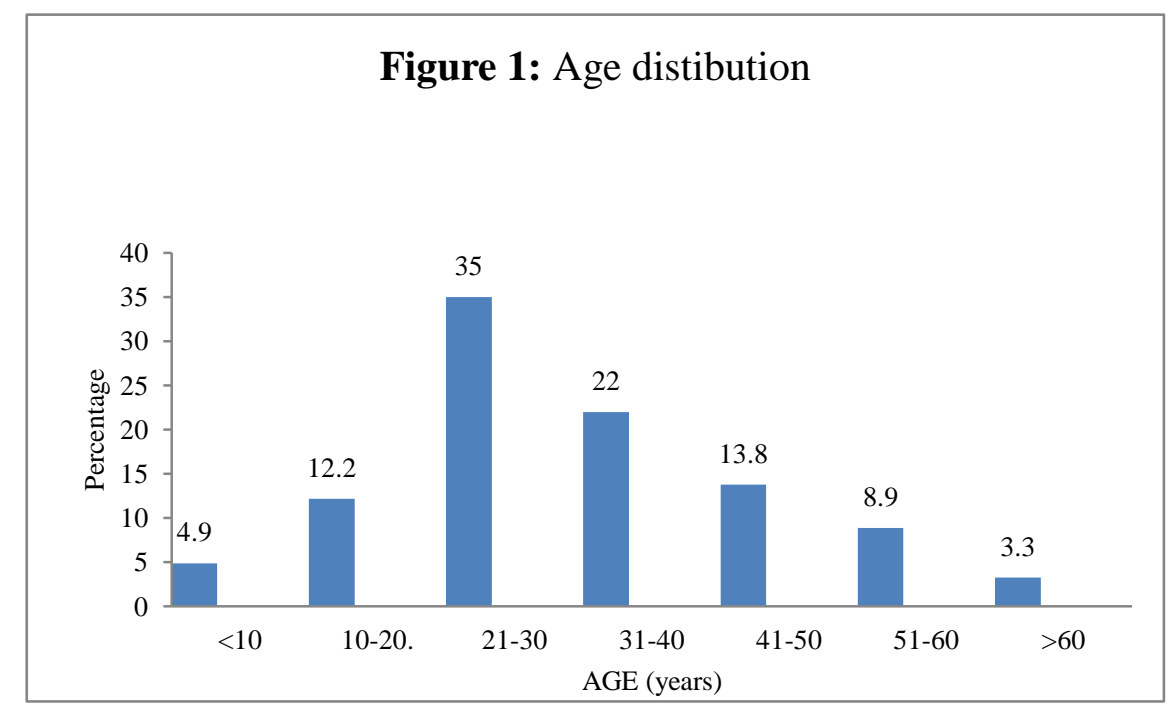

Table 2: Age distribution in various classes

\begin{tabular}{|c|c|c|c|c|c|c|c|c|}
\hline \multirow[t]{2}{*}{$\begin{array}{l}\text { HAAS } \\
\text { CLASS }\end{array}$} & \multicolumn{7}{|c|}{ Age (in years) } & \multirow[b]{2}{*}{ Tota } \\
\hline & $<10$ & $10-20$ & $21-30$ & $31-40$ & $41-50$ & $51-60$ & $>60$ & \\
\hline & 4 & 4 & 13 & 4 & 4 & 3 & 2 & 34 \\
\hline II & 0 & 0 & 1 & 0 & 0 & 1 & 0 & 2 \\
\hline $\begin{array}{l}\text { II } \\
\text { I }\end{array}$ & 0 & 0 & 4 & 4 & 1 & 2 & 0 & 11 \\
\hline $\begin{array}{l}\text { I } \\
\text { V }\end{array}$ & 2 & 10 & 11 & 13 & 9 & 1 & 2 & 48 \\
\hline $\mathrm{V}$ & 0 & 1 & 14 & 6 & 3 & 4 & 0 & 28 \\
\hline Total & 6 & 15 & 43 & 27 & 17 & 11 & 4 & 123 \\
\hline
\end{tabular}




\section{Sex Distribution}

Out of the 123 cases studied, males predominated $(70.7 \%, n=87)$ with a male: female ratio being $2.4: 1$ (fig 2)

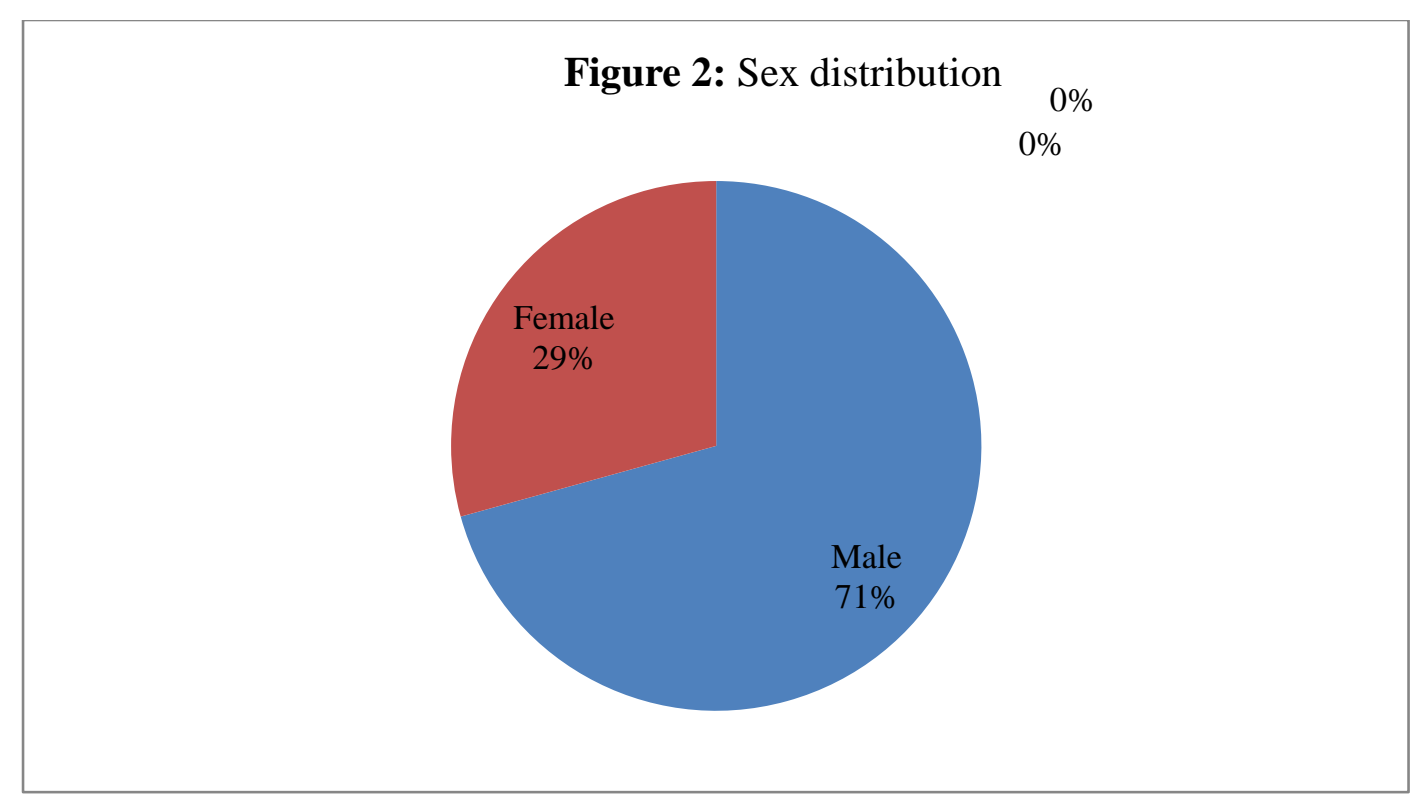

\section{Clinical and Laboratory Features}

Among the three parameters (hypertension, hematuria and proteinuria) studied, hypertension was found in 48(39\%) cases (Fig 3), hematuria in $53(43 \%)$ cases (Fig 5) and proteinuria in 51(42\%) cases (Fig 7).Among the various classes of $\operatorname{IgAN}$, hypertension was commonly seen in Class V $(82 \%)$ (Fig 4), hematuria was commonly seen in Class IV (62.5\%) (Fig 6) and proteinuria was commonly seen in Class V (53.5\%) (Fig 8). Combination of hematuria and proteinuria was the most combined clinical presentation (Fig 9).

Figure 3: Percentage of cases with Hypertension

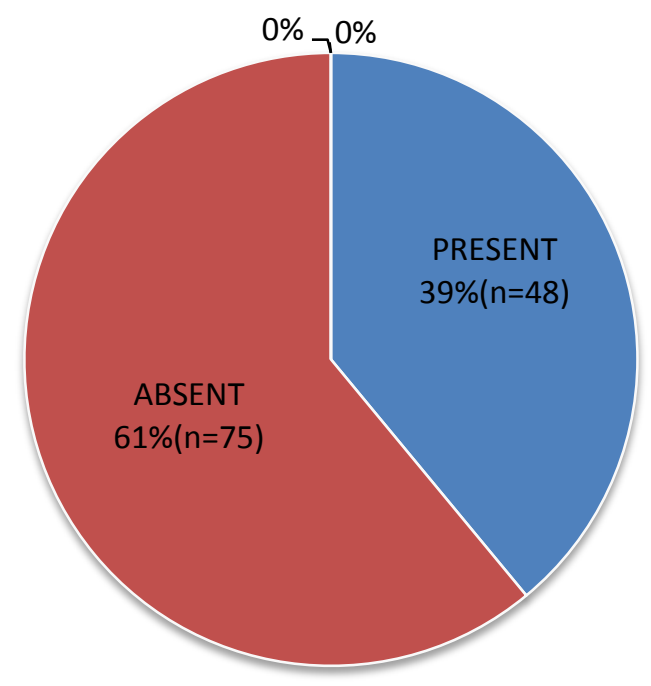




\section{JMSCR VoI||07||Issue||07||Page 334-342||July}

Figure 4: Hypertension among various classes of IgAN

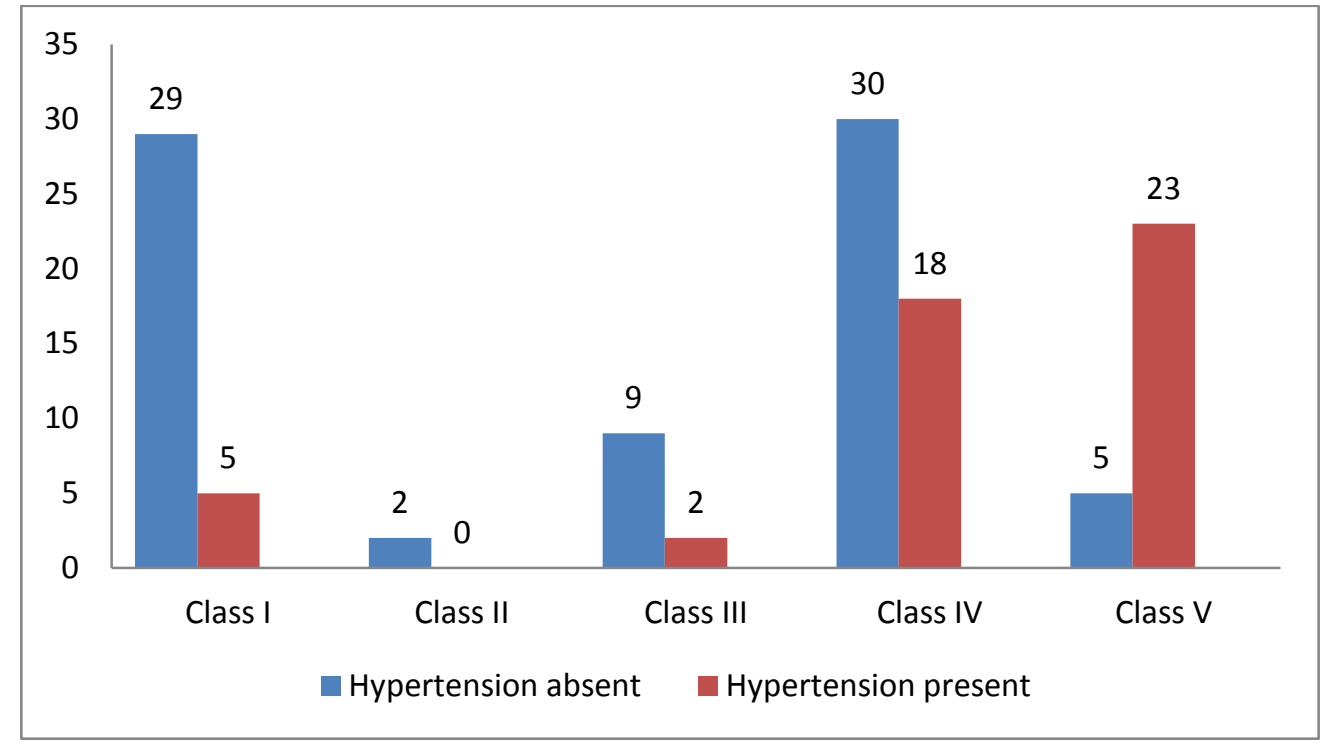

Figure 5: Percentage of cases with Hematuria

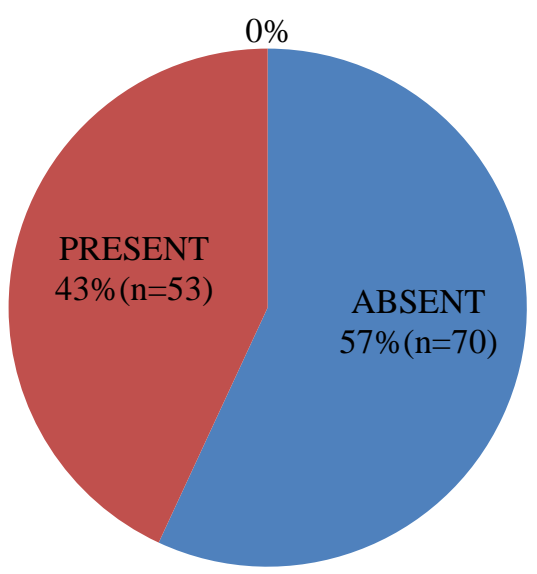

Figure 6: Hematuria among various classes of IgAN

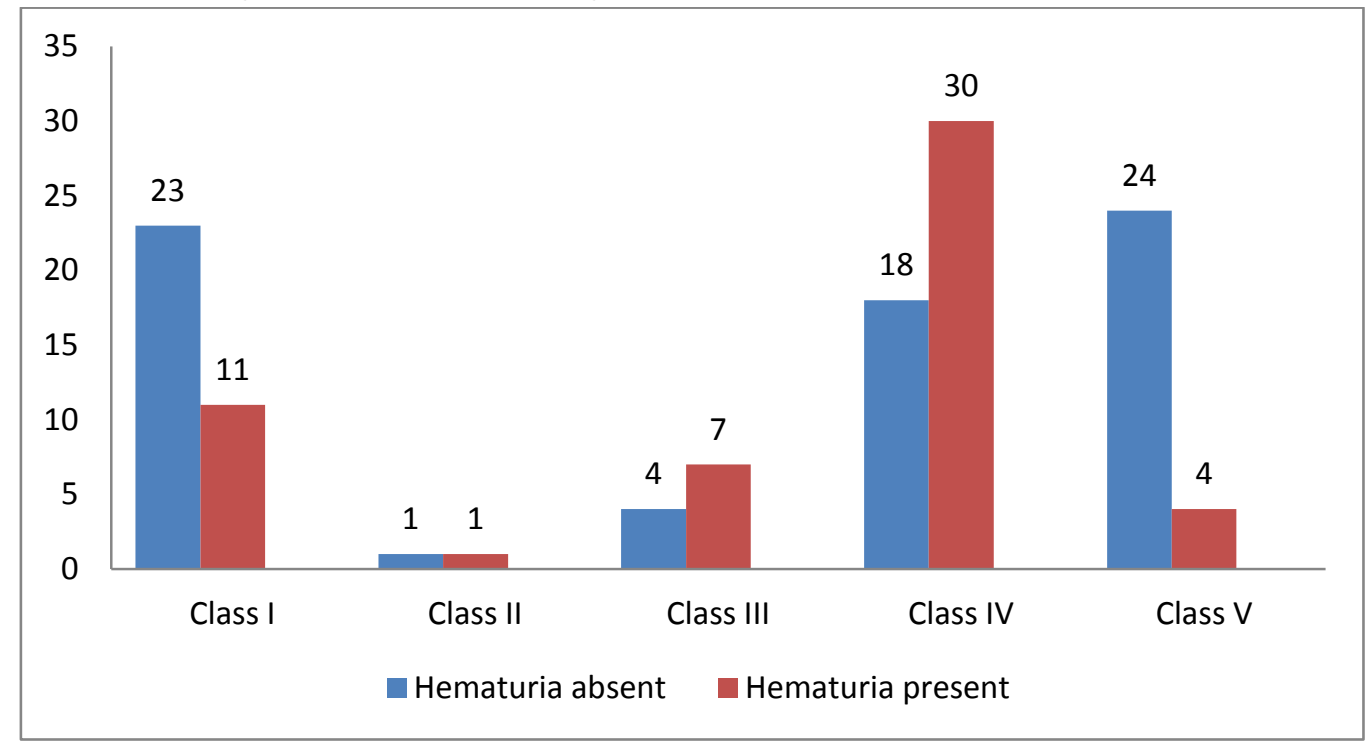


Figure 7: Percentage of cases with Proteinuria

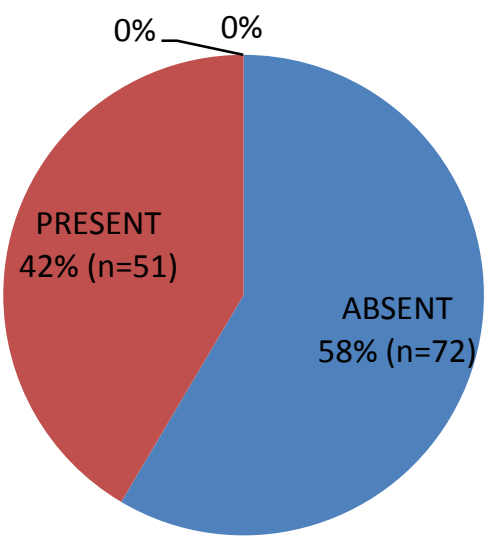

Figure 8: Proteinuria among various classes of IgAN

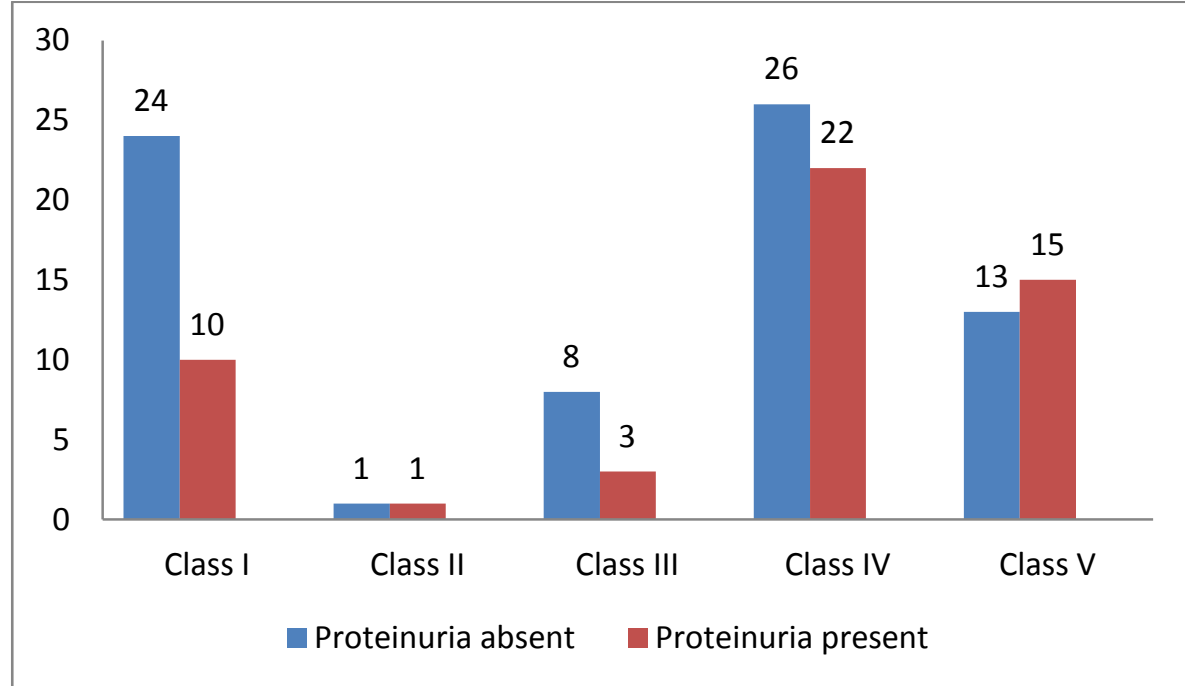

Fig 9: Percentage of cases with hematuria, hypertension and proteinuria in combinations

\begin{tabular}{|c|c|c|c|c|}
\hline \multicolumn{5}{|l|}{$100 \%$} \\
\hline \multicolumn{5}{|l|}{$90 \%$} \\
\hline \multicolumn{5}{|l|}{$80 \%$} \\
\hline \multicolumn{5}{|l|}{$70 \%$} \\
\hline \multicolumn{5}{|l|}{$60 \%$} \\
\hline \multicolumn{5}{|l|}{$50 \%$} \\
\hline \multicolumn{5}{|l|}{$40 \%$} \\
\hline \multicolumn{5}{|l|}{$30 \%$} \\
\hline \\
\hline \multicolumn{5}{|l|}{$10 \%$} \\
\hline & $\begin{array}{l}\mathrm{HT}+\text { Hematuria+Protei } \\
\text { nuria }\end{array}$ & $\mathrm{HT}+$ Proteinuria & $\begin{array}{c}\mathrm{HT}+\mathrm{Hematuria}+\text { Protei } \\
\text { nuria }\end{array}$ & $\begin{array}{l}\text { Hematuria+proteinur } \\
\text { ia }\end{array}$ \\
\hline Class V & 6 & 12 & 1 & 2 \\
\hline Class IV & 2 & 8 & 8 & 6 \\
\hline Class III & 2 & 4 & 6 & 3 \\
\hline Class II & 0 & 0 & 1 & 1 \\
\hline - Class I & 0 & 1 & 2 & 18 \\
\hline
\end{tabular}




\section{Discussion}

123 cases of Primary IgAN have been studied during the 10 year period at St. John's Medical College \& Hospital, Bangalore. These cases were analysed with respect to their clinical presentation and immunological and morphological features based on Haas classification of IgAN.

Age: The study group had a wide range of age, ranging from 4 years to 70 years with the largest incidence in the $20-30$ years age group (35\%) and an average age of 32.74 years which is in concordance with other Indian studies ${ }^{11,12,13}$ which is atleast 5 to 6 years younger than the values quoted in the western literature.

Sex: Out of the 123 cases studied, males predominated $(70.7 \%, \mathrm{n}=87)$ with a male: female ratio being 2.4:1 which is in concordance with other Indian studies by Vanikar et $\mathrm{al}^{14}$, Chako et $\mathrm{al}^{13}$ and slightly higher male predominance was reported by Mittal et $\mathrm{al}^{13}$ and other western studies by Haas et $\mathrm{al}^{17}$.

Clinical and laboratory features: Among the three parameters (hypertension, hematuria and proteinuria) studied, hypertension was found in $48(39 \%)$ cases, hematuria in $53(43 \%)$ cases and proteinuria in $51(42 \%)$ cases .Hypertension was found in $39 \%$ of cases which is in concordance with study by Meraet $\mathrm{al}^{15}$ (42\%). A higher incidence of hypertension was reported by Chakoet $\mathrm{al}^{13}$ (58\%), Mittal et $\mathrm{al}^{11}(78.8 \%)$ and Haas et $\mathrm{al}^{17}(50 \%)$. Hematuria was found in $43 \%$ of cases which is in concordance with study by Chandrikaet $\mathrm{al}^{12}$ and Koyama et $\mathrm{al}^{16}$ (49\%). A higher incidence was found in studies by Chako et $\mathrm{al}^{13}(69 \%)$, Mittal et $\mathrm{al}^{11}(81 \%)$ and Haas et al ${ }^{17}$ (100\%). Proteinuria was found in $42 \%$ of cases which is in concordance Koyama et $\mathrm{al}^{16}(40.6 \%)$, Haas et $\mathrm{al}^{17}(36 \%)$ and Chandrika et al ${ }^{12}(36.7 \%)$. A higher incidence of was found in study by Chakoet $\mathrm{al}^{13}(55 \%)$ and a lower incidence was found in studies by Mittal et $\mathrm{al}^{11}$ (23.1\%) and Koyama et $\mathrm{al}^{16}(11 \%)$.Among the various classes of IgAN, hypertension was commonly seen in Class V (82\%) hematuria was commonly seen in Class IV (62.5\%) and proteinuria was commonly seen in Class V (53.5\%).

Table 3: Comparison of demographics, laboratory and histopathological findings with different Indian study groups

\begin{tabular}{|c|c|c|c|c|c|}
\hline & $\begin{array}{c}\text { Present } \\
\text { study }\end{array}$ & $\begin{array}{l}\text { Mittal } \\
\text { et }^{11}{ }^{11}\end{array}$ & $\begin{array}{l}\text { Chako } \\
\text { et al }^{13}\end{array}$ & $\begin{array}{l}\text { Chandrika } \\
\text { et }^{12}{ }^{12}\end{array}$ & $\begin{array}{l}\text { Vanikar } \\
\text { et al }^{14}\end{array}$ \\
\hline Mean age (years) & 32.74 & 29.9 & 32 & $3^{\text {rd }}$ decade & \\
\hline Male: female ratio & $2.4: 1$ & $4.4: 1$ & $1.85: 1$ & $1.5: 1$ & $2.6: 1$ \\
\hline Hypertension (\%) & 39 & 78.8 & 58 & 3.5 & - \\
\hline Haematuria (\%) & 43 & 81 & 69 & 49.3 & 100 \\
\hline Proteinuria (\%) & 42 & 23.1 & 55 & 36.7 & - \\
\hline Most frequent class & IV & V & & II & II \\
\hline
\end{tabular}

Table 4: Comparison of demographics, laboratory and histopathological findings with different Western study groups

\begin{tabular}{|l|c|c|c|c|}
\hline & Present study & Haas et al & Mera et al $^{17}$ & Koyama et al $^{16}$ \\
\hline Mean age (years) & 32.74 & 39.1 & 35.4 & \\
\hline Male: female ratio & $2.4: 1$ & $5.6: 1$ & $0.86: 1$ & $1.23: 1$ \\
\hline Hypertension (\%) & 39 & 50 & 42 & \\
\hline Haematuria (\%) & 43 & 94 & 100 & 49.4 \\
\hline Proteinuria (\%) & 42 & 36 & 11 & 40.6 \\
\hline Most frequent class & IV & III & & IV \\
\hline
\end{tabular}




\section{Conclusions}

To summarize IgA nephropathy is a disease of men in their mid 30s, which has a nephriticnephrotic presentation and is morphologically a proliferative glomerulopathy, which is also the presentation in our study but with a higher incidence of advanced sclerosis. This is a finding of the utmost importance as a direct implication is that our patients are barely amenable to any form of therapy when they reach the hospital. This calls for early intervention strategies as well as screening programmes, not only to identify and treat the patients, but also for a better understanding of the factors which lead to this rapid and early progression. Geographical variation, genetic factors and biopsy practice also play an important role in the prevalence of $\operatorname{IgA}$ nephropathy. Various incidence of clinical presentation, laboratory features and histopathological findings as suggested by various studies depend on the geographical variation, genetics and biopsy practice.

\section{References}

1. D'Amico G. The commonest glomerulonephritis in the world: IgA nephropathy. Q J Med 1987;64:709-727.

2. J Charles Jennette. IgA nephropathy and HenochSconleinPurpura. In:FogoA, BruijnJA, ColvinRB, JennetteJc, editors. Fundamentals of Renal Pathology. Sringer 2006:61-68.

3. Woo KT, Chiang GS, Pall A, et al. The changing pattern of glomerulonephritis inSingapore over the past two decades. ClinNephrol 1999;52:96-102.

4. Okada K, Funai M, Kawakami K, et al. IgA nephropathy in Japanese children and adults: a comparative study of clinicopathological features. Am J Nephrol 1990;10:191-197.

5. Li PK, Ho KK, Szeto CC, et al. Prognostic indicators of $\operatorname{IgA}$ nephropathy in the Chinese clinical and pathological perspectives. Nephrol Dial Transplant 2002;17:64-69.

6. Siddappa S, Kowsalya R, Mythri KM. IgA nephropathy in a tertiary care center from south India. Ind J Nephrolgy 2011;21(4):230-34.

7. Jonathan Barratt, Frank Eitner, John Feehally and J"urgenFloege. Immune complex formation in IgA nephropathy: a case of the 'right'antibodies in the 'wrong' place at the 'wrong' time?.Nephrol Dial Transplant 2009;24:3620-3623

8. Haas M. Histologic subclassification of IgA nephropathy: A clinicopathologic study of 244 cases. Am J Kidney Dis 1997;29:829.

9. Ibels LS, Gyory AZ. IgA nephropathy: Analysis of the natural history, important factors in the progression of renal disease, and a review of the literature. Medicine 1994;73:79

10. Clarkson AR, Seymour AE, Thompson AJ, et al. IgA nephropathy: A syndrome of uniform morphology, diverse clinical features and uncertain prognosis. ClinNephrol 1977;8:459.

11. Mittal N, Joshi K, Rane S, Nada R, Sakhuja V. Primary IgA nephropathy in north India: Is it different? Postgrad Med J 2012;88:15-20.

12. Chandrika BK. Non-neoplastic renal diseases in Kerala, India-analysis of 1592 cases, a two year retrospective study. Indian J PatholMicrobiol. 2007;50(2):300 302.

13. Chacko B, John GT, Neelakantan N, et al. Presentation, prognosis and outcome of IgA nephropathy in Indian adults. Nephrology (Carlton). 2005;10(5):496503.

14. Vanikar AV, Kanodia KV, Patel RD, Trivedi HL. Primary IgA nephropathy in Western India. Indian J Nephrol. 2005; 15:227-231. 
15. Golay V, Trivedi M, Abraham A, RoychowdharyA,Pandey R. The spectrum of glomerular diseases in a single center: A clinicopathological correlation Indian $\mathrm{J}$ Nephrol 2013;23(3):168-175.

16. Koyama A, Igarashi M, Kobayashi M. Natural history and risk factors for immunoglobulin A nephropathy in Japan. Research Group on Progressive Renal Diseases. Am J Kidney Dis 1997;29:52632.

17. Haas M, Rahman MH, Cohn RA, et al. IgA nephropathy in children and adults:comparison of histologic features and clinical outcomes. Nephrol Dial Transplant2008;23:2537-2545. 